\title{
Association of Reduced Lung Function With Major Depressive Disorder
}

\author{
Khandaker Nadia Afreen ${ }^{1}$, Masud Imtiaz ${ }^{2}$, Mahadi Abdur Rouf ${ }^{3}$, Rono Mollika ${ }^{4}$,Lutfun Nahar ${ }^{5}$, Richmond \\ Ronald Gomes ${ }^{6}$
}

\begin{abstract}
Background: Major Depressive Disorder (MDD) is associated with reduced lung function.

Objectives: To observe \& compare $\mathrm{FEF}_{25 \%-75 \%}$ in Major Depressive Disorder patients with control group.

Methods: This prospective study was carried out in the Department of Physiology, Bangabandhu Sheikh Mujib Medical University (BSMMU) from January to December, 2014 to assess the lung function status in newly diagnosed MDD patients. For this, 30 newly diagnosed female MDD patients (group B), aged 20 to 50 years were enrolled from the Department of Psychiatry of BSMMU. For control (group A) age, BMI, and occupation matched 30 apparently healthy females were randomly selected by personal contact. $F E F_{25 \%-75 \%}$ of all subjects were assessed by a portable digital spirometer (PONY FX, Cosmed, Italy). For statistical analysis, ANOVA, Independent sample 't' test were done and $p$ value $\leq 0.05$ was considered as level of significance.
\end{abstract}

Results: $F E F_{25 \%-75 \%}$ was significantly lower ( $p \leq 0.001$ ) in all MDD patients than control.

Conclusion: From this study it may be concluded that the ventilatory lung function is significantly reduced in newly diagnosed MDD patients.

Key words: Major Depressive Disorder (MDD), Forced Expiratory flow (FEF $25-75 \%$.

\section{Introduction:}

Depression is the most common chronic condition next to hypertension in general medical practice. Out of ten patients visiting psychiatric outpatient department, one patient is suffering from major depression. ${ }^{1}$

Major Depressive Disorder (MDD) is defined by depressed mood or loss of interest in nearly all activities or both for at

1. Dr. Khandaker Nadia Afreen, Assistant Professor, Department of Physiology, Z H Sikder Women's Medical College Hospital, Dhaka.

2. Dr. Masud Imtiaz, Associate Professor, Department of Physiology, Khulna City Medical College, Khulna.

3. Dr. Mahadi Abdur Rouf, Assistant Professor, Department of Physiology, Northern International Medical College, Dhaka.

4. Dr. Rono Mollika, Assistant Professor, Department of Physiology, Enam Medical College, Dhaka.

5. Dr. Lutfun Nahar, Assistant Professor, Department of Physiology, Z H Sikder Women's Medical College Hospital, Dhaka.

6. Dr. Richmond Ronald Gomes, Assistant Professor, Department of Medicine, Ad-din Sakina Medical College, Jessore.

\section{Corresponding Author:}

Dr. Khandaker Nadia Afreen

Assistant Professor

Department of Physiology

Z H Sikder Women's Medical College Hospital, Dhaka.

Email: drnadiaafreen@yahoo.com.

Phone: +8801715566868 least two weeks, accompanied by a minimum of three or four of the following symptoms (for a total of at least five symptoms altogether) such as insomnia or hypersomnia, feeling of worthlessness or excessive guilt, fatigue or loss of energy, diminished ability to think or concentrate, substantial change in appetite or weight, psychomotor agitation or retardation and recurrent thoughts of death or suicide. ${ }^{1}$

\section{Introduction:}

Depression is a major cause of morbidity worldwide. The WHO ranks depression as the fourth leading cause of disability worldwide and by 2020, it will be the second leading cause. Population studies have consistently shown major depression is about twice as common in women as in men, although the underlying cause and factor is unclear. Old age people are more affected. People are most likely to suffer their first depressive episode at about 25.7 years in high income and 24 years in low to middle income country ${ }^{2}$.

Depression may affect almost all the organs of the body and is responsible for different diseases such as myocardial infarction (MI), other coronary artery diseases, stroke, diabetes, kidney diseases, arthritis, Parkinson's disease and other autoimmune diseases ${ }^{3}$.

Researchers found depressed lung function in depressive illness patients which is more in $\mathrm{MDD}^{4}$. Carroll $\mathrm{D}$ et al found that MDD was associated with lower $\mathrm{FEV}_{1}{ }^{5}$. Whereas Calikoglu et al. found no difference in lung function in MDD patients in comparison to control ${ }^{6}$. 


\section{Methods}

This study was carried out in the Department of Physiology of BSMMU, Dhaka, between January to December 2014. Thirty female newly diagnosed Major Depressive Disorder patients aged 20 to 50 years constituted study group (Group B). Thirty age, sex, BMI matched healthy subjects were taken as control (Group A). Study protocol was approved by Institutional Review Board (IRB) of BSMMU, Shahabag, Dhaka, Bangladesh. Patients were randomly selected from the OPD of Psychiatry Department of BSMMU, Dhaka. Subjects with pregnancy and lactation and evidence of lung diseases, coronary heart disease, diabetes mellitus, neurological disorders, smokers were excluded from the study. An informed written consent was taken from the willing participants. A detail personal, medical, family, socioeconomic, occupational and drug history were recorded in a preformed questionnaire and thorough physical examinations were done and documented. For this assessment of lung function $\mathrm{FEF}_{25 \%-75 \%}$ of all the subjects were recorded by a digital spirometer. Data were expressed as mean $\pm \mathrm{SE}$ (Standard Error) and also in frequency percent. Independent sample ' $t$ ' test was done to compare between the groups by using SPSS (Version 16). In the interpretation of results, $p$ value $<0.05$ was accepted as level of significance.

\section{Result}

The mean \pm SE of age, BMI \& Systolic Blood Pressure (SBP) \& Diastolic Blood Pressure (DBP) of all the subjects was almost similar in all the subjects \& these values where non-significant between 2 groups (Table I).

Table I: Age, BMI and BP in different groups $(n=60)$

\begin{tabular}{|c|c|c|c|c|}
\hline Groups & $\begin{array}{l}\text { Age } \\
\text { (years) }\end{array}$ & $\begin{array}{l}\text { BMI } \\
(\mathrm{Kg} / \mathrm{m} 2)\end{array}$ & $\begin{array}{l}\text { SBP } \\
(\mathrm{mmHg})\end{array}$ & $\begin{array}{l}\text { DBP } \\
(\mathrm{mmHg})\end{array}$ \\
\hline $\mathrm{A}(\mathrm{n}=30)$ & $\begin{array}{l}34.40 \pm 1.72 \\
(20-50)\end{array}$ & $\begin{array}{l}27.03 \pm 0.64 \\
(20.2-33.7)\end{array}$ & $\begin{array}{l}121 \pm 1.79 \\
(100-140)\end{array}$ & $\begin{array}{l}80.83 \pm 1.66 \\
(60-95)\end{array}$ \\
\hline $\mathrm{B}(\mathrm{n}=30)$ & $\begin{array}{l}34.13 \pm 1.49 \\
(22-50)\end{array}$ & $\begin{array}{l}27.51 \pm 0.56 \\
(20.16-32.2)\end{array}$ & $\begin{array}{l}120 \pm 1.86 \\
(100-140)\end{array}$ & $\begin{array}{l}79.00 \pm 1.73 \\
(60-90)\end{array}$ \\
\hline \multicolumn{5}{|c|}{ Statistical analysis } \\
\hline $\begin{array}{l}\text { p value } \\
\text { Groups }\end{array}$ & Age & BMI & SBP & DBP \\
\hline A vs. B & $0.907^{\mathrm{ns}}$ & $0.574^{\mathrm{ns}}$ & $0.654^{\mathrm{ns}}$ & $0.449^{\mathrm{ns}}$ \\
\hline
\end{tabular}

$\mathrm{BMI}=$ Body Mass Index, SBP= Systolic Blood Pressure, DBP=Diastolic Blood Pressure

Group A: Apparently healthy subjects (control)

Group B: Newly diagnosed MDD patients before medication

ns $=$ Nonsignifiant $(\mathrm{p}>0.05), \mathrm{n}=$ Number

The percentage of predicted values of $\mathrm{FEF}_{25 \%-75 \%}$ was significantly lower $(\mathrm{P}<0.000)$ in study group than that of control (Table II). Table II: Percentage of predicted values of $\mathrm{FEF}_{25 \%-75 \%}$ in different groups

\begin{tabular}{llll}
\hline Parameters & $\begin{array}{l}\text { Group A } \\
(\mathbf{n = 3 0 )}\end{array}$ & $\begin{array}{l}\text { Group B } \\
(\mathbf{n = 3 0 )}\end{array}$ & P value \\
\hline $\mathbf{F E F}_{\mathbf{2 5} \%}$ & $71.63 \pm 3.42$ & $41.33 \pm 4.24$ & $0.000^{* * *}$ \\
& $(29-101)$ & $(10-90)$ & $0.000^{* * *}$ \\
$\mathbf{F E F}_{\mathbf{5 0} \%}$ & $71.13 \pm 3.69$ & $36.20 \pm 4.54$ & $0.001^{* * *}$ \\
$\mathbf{F E F}_{\mathbf{7 5} \%}$ & $(26-102)$ & $(4-95)$ & \\
\hline
\end{tabular}

Group A: Apparently healthy subjects (control)

Group B: Newly diagnosed MDD patients before medication

$* * *=$ Significant $(\mathrm{p} \leq 0.001)$

$\mathrm{n}=$ Number 


\section{Discussion}

The present study has been undertaken to observe pulmonary functions in 30 newly diagnosed female MDD patients. Pulmonary functions were assessed by measuring $\mathrm{FEF}_{25 \%-75 \%}$ with a portable micro spirometer. $\mathrm{FEF}_{25-75 \%}$ actually represents Force Expiratory Flow in the middle half of FVC. Different studies were done to see different effects on others parameters like FVC, $\mathrm{FEV}_{1}$, PEFR of lung function status. But very few studies were done to see different effects on Force Expiratory Flow in the middle half of FVC. This variable were also studied initially in 30 apparently healthy subjects for comparison. All data in the healthy subjects were normally distributed. In this study, value of all the lung function variable of healthy subjects were within physiological limit 7,8. Again, both the groups (control and study) were comparable in their biological characteristics as there was no significant difference in the confounding variables such as age, BMI and occupation. However, to exclude the effect of age and BMI on the measured values of ventilatory variables, measured values as the percentage of predicted values were used for analysis. Different researchers found that pulmonary functions are significantly reduced in patients with depressive illness especially in major depressive disorder patients. Islam and his colleagues investigated lung function by spirometry in depressive disorder patients and found lung function parameters were significantly lower in depressive disorder patients in comparison to healthy subjects ${ }^{4}$. Another study was done on US soldiers experience to find out association between MDD with lung function. But they did not find any significant association between MDD and poor lung function ${ }^{5}$. Calikoglu and his colleagues investigated lung function test by spirometry in 30 female MDD patients ${ }^{6}$. After comparing with control group, they found that dyspnea was higher in MDD. The apparent effect of depression on poor lung function in MDD patients may be explained by the reduced psychomotor activity along with poor respiratory muscle strength in depressive illness ${ }^{9}$.

\section{Conclusion}

The result of this study suggests that ventilatory function of lung are significantly reduced in MDD patients.

\section{References :}

1. Whooley, MA and Simon, GE. Managing depression in medical science. N Engl J Med. 2000;. 343: 1942-50.

2. Bromet E, Andrade LH, Hwang I, Sampson, NA, Alonso J, Girolamo Gd, et. al (2011). Cross national epidemiology of DSM IV major depressive episode, BMC Medicine.9:90.

3. Goldberg, S . Goldberg, S depression scale. Ann of Biol Res. 2012;3(9): 4564-73.

4. Islam, S, Jahan, N, sultana, N, Akhter, R.FVC, FEV1 and $\mathrm{FEV} 1 / \mathrm{FVC} \%$ in patients with depressive illness and their relationships with the level of depression. J Bangladesh soc Physiol 2010; 5(2): 94-100.

5. Carroll, D, Phillips, AC, Gale, CR, Batty, GD Generalized anxiety disorder is associated with reduced lung function in the Vietnam experience study. Psychosom med. 2011;73:716-20.

6. Calikoglu, M, Sahin, G, Yazici, AE, Yazici, K and Ozisik, S .Pulmonary muscle strength, pulmonary function tests and dyspnea in women with major depression. J women health.2004;13 (1):1-7.

7. American Thoracic Society. Medical sections of the American Lung Association. Am Rev Respir Dis. 1991;144: 1202-18.

8. Global Initiative for Chronic obstructive Lung Disease. Spirometry for Health Care Providers 2010; [internet sited by May 23, 2013] available from $h t t p / / w w w$. Goldcopd. Org.

9. Kupfer, DJ, Weiss, BL, Foster, FG, Detre, TP, Delgado, Portland, RM . Psychomotor activity in affective states. Arch Gen Psy.1974; 30(6): 765-8. 